\begin{tabular}{l}
\hline MATAPPA: Jurnal Pengabdian Kepada Masyarakat \\
Volume 2 | Nomor $1 \mid$ Maret |2019 \\
e-ISSN: 2614-6673 dan p-ISSN: $2615-5273$ \\
\begin{tabular}{|l|l|} 
(c) (1) This work is licensed under a Creative Commons Attribution \\
4.0 International License
\end{tabular}
\end{tabular}

\title{
Penerapan Komunikasi Efektif Dalam Proses Pembelajaran Dan Bimbingan Konseling Pada Siswa SMA
}

\section{Sepni Yanti}

\begin{tabular}{ll}
\hline \hline Keywords : & Abstrak. Komunikasi yang baik dapat dilakukan jika \\
Komunikasi; & guru,murid dan kepala sekolah serta seluruh personil \\
Efektif; & yang berhubungan dengan sekolah saling mengerti \\
Bimbingan Konseling. & akan pentingnya komunikasi yang efektif dan baik. \\
& Guru atau dosen yang mengajar terkadang tidak \\
& mempunyai bakat atau punya keterbatasan yang \\
& rendah dalam hal berkomunikasi yang baik dan efektif. \\
Corespondensi Author & Tujuan pengabdian masyarakat ini ,agar guru dan \\
Universitas Indraprasta PGRI & siswa dapat memahami dan mengaplikasikan \\
Jakarta & komunikasi yang efektif yng berkaitan dengan \\
Email: sepniyanti@gmail.com & pembelajaran dan bimbingan konseling disekolah. \\
& Kegiatan akan diadakan pada awal Mei sampai dengan \\
History Artikel & Agustus 2018. Peserta adalah siswa SMA Attaqwa dan \\
Received: $30-01-2019 ;$ & SMK Insan Mulia. Hasil kegiatan ini adalah para guru \\
Reviewed: $12-02-2019 ;$ & dan siswa lebih terbantu dengan adanya bimbingan \\
Revised: $20-03-2019 ;$ & konseling dan kegiatan peningkatan komunikasi yang \\
Accepted: $24-03-2019 ;$ & baik dan efektif. Siswa lebih merasa dihargai dan \\
Published: $28-03-2019$ & diperhatikan,karena masalah belajar dapat diatasi \\
& dengan baik. \\
\hline \hline
\end{tabular}

\section{PENDAHULUAN}

Pada pembelajaran saat ini,masih didapati berbagai permasalahan yang timbul karena komunikasi. Dalam hal ini termasuk pengajar ,murid dan kepala sekolah. Komunikasi yang baik dapat dilakukan jika guru,murid dan kepala sekolah serta seluruh personil yang berhubungan dengan sekolah saling mengerti ,akan pentingnya komunikasi yang efektif dan baik. Guru atau dosen yang mengajar terkadang tidak mempunyai bakat atau punya keterbatasan yang rendah dalam hal berkomunikasi yang baik dan efektif.

Komunikasi merupakan salah satu kebutuhan manusia sekaligus dasar eksistensi suatu masyarakat yang dapat menentukan struktur suatu masyarakat dalam suatu lingkungan. Suranto ( 2011) berpendapat bahwa iklim komunikasi berhubungan dengan motivasi guru,dan guru akam termotivasi untuk meningkatkan kinerjanya, pada saat guru merasakan iklim komunikasi yang baik. Hasil penelitian sebelumnya dari Yuli Setyowati (2005), menunjukkan bahwa, penerapan pola komunikasi keluarga sebagai bentuk interaksi antara orang tua dengan anak maupun antar anggota keluarga memiliki implikasi terhadap proses perkembangan emosi anak. Dalam proses komunikasi tersebut, anak akan belajar mengenal dirinya maupun orang lain, serta memahami perasaannya sendiri maupun orang lain .Menurut hasil pengamatan yang dilakukan peneliti melalui observasi kelas dan wawancara dengan guru mata pelajaran bimbingan konseling dan beberapa guru lainya semester genap di SMA Attaqwa dan SMK Insan Mulia tahun pelajaran 2017/2018 menunjukkan kurang 
optimalnya komunikasi antar guru dan siswa . Berdasarkan informasi guru BK di sekolah, perlu adanya pemahaman bersama ,akan pentingnya komunikasi yang efektif. Komunikasi merupakan faktor penting dalam pembelajaran di sekoah (Widiyarto, S., \& Ati, A. P. 2018).

Pembelajaran akan kurang maksimal dan perlu penguatan dari pihak sekolah dan pihak lain seperti yayasan ,komite dan yang lainya. Peran serta (keaktifan) guru BK saja,tidaklah cukup dan perlu dibantu, bekerjasama dalam memberikan pemahaman komunikasi yang efektif. Peran para guru juga diharapkan dapat membantu kelancaran proses belajar mengajar, Yanti, S. (2019).

Tujuan dari kegiatan pengabdian masyarakat ini adalah,1) memberikan pemahaman dan penjelasan tentang berkomunikasi yang efektif ,2) siswa dan guru mendapatkan bahasa yang standard dan baku, 3) untuk memperbaiki kualitas pembelajaran dan memberikan bimbingan konseling di kelas.

Selanjutnya komunikasi adalah suatu proses penyampaian informasi (pesan, ide, gagasan) dari satu pihak kepada pihak lain. Hal ini penting bagi mitra karena pola komunikasi yang instant dan singkat,membuat anak kurang mendapat perhatian dan bimbingan yang cukup dari orang tua atau guru disekolah.Sehingga perlu adanya pendekatan komunikasi yang tepat dan efesien. Menurut data dari guru BK, beberapa orangtu siswa sangat sibuk bekerja baik yah maupn ibu ,sehingga perlu adanya penerapan yang tepat. Komunikasi pada umumnya, dilakukan secara lisan atau verbal yang dapat dimengerti oleh kedua belah pihak. apabila tidak ada bahasa verbal yang dapat dimengerti oleh keduanya, komunikasi masih dapat dilakukan dengan menggunakan gerakgerik badan, menunjukkan sikap tertentu, misalnya tersenyum, menggelengkan kepala, mengangkat bahu. Cara seperti ini disebut komunikasi nonverbal. Adapun unsur-unsur komunikasi yang perlu diketahui menurut Ron Ludlow, Fergus Panton (1992) dalam buku yang berjudul The Essence of Effective Communication adalah, 1) komunikator,2) komunikan,3) media ,4) pesan .

Dengan berkomunikasi, kita dapat menjalin hubungan, saling pengertian dengan orang lain karena komunikasi memiliki beberapa fungsi yang sangat penting, di antaranya ,1) fungsi informasi, 2)fungsi ekspresi,3) fungsi kontrol, 4) sosial dan 5) ekonomi.
Di dalam komunikasi selalu ada hambatan yang dapat mengganggu kelancaran jalannya proses komunikasi . Sehingga informasi dan gagasan yang disampaikan tidak dapat diterima dan dimengerti dengan jelas oleh penerima pesan atau receiver. Menurut Ron Ludlow \& Fergus Panton, ada hambatanhambatan yang menyebabkan komunikasi tidak efektif yaitu adalah, 1) status effect, adanya perbedaaan pengaruh status sosial yang dimiliki setiap manusia.Misalnya karyawan dengan status sosial yang lebih rendah harus tunduk dan patuh apapun perintah yang diberikan atasan. karyawan tersebut tidak dapat atau takut mengemukakan aspirasinya atau pendapatnya.

2) Semantic Problems, aktor semantik menyangkut bahasa yang dipergunakan komunikator sebagai alat untuk menyalurkan pikiran dan perasaanya kepada komunikan. Demi kelancaran komunikasi seorang komunikator harus benar-benar memperhatikan gangguan sematis ini, sebab kesalahan pengucapan atau kesalahan dalam penulisan dapat menimbulkan salah pengertian (misunderstanding) atau penafsiran (misinterpretation) yang pada gilirannya bisa menimbulkan salah komunikasi (miscommunication). Misalnya kesalahan pengucapan bahasa dan salah penafsiran seperti contoh : pengucapan demonstrasi menjadi demokrasi, kedelai menjadi keledai dan lain-lain 3) perceptual distorsion, perceptual distorsion dapat disebabkan karena perbedaan cara pandangan diri sendiri dan perbedaaan cara berpikir serta cara mengerti yang sempit terhadap orang lain. Sehingga dalam komunikasi terjadi perbedaan persepsi dan wawasan atau cara pandang antara satu dengan yang lainnya, 4) cultural differences, hambatan yang terjadi karena disebabkan adanya perbedaan kebudayaan, agama dan lingkungan sosial. Dalam suatu organisasi terdapat beberapa suku, ras, dan bahasa yang berbeda. Sehingga ada beberapa kata-kata yang memiliki arti berbeda di tiap suku. Seperti contoh : kata "jangan" dalam bahasa Indonesia artinya tidak boleh, tetapi orang suku jawa mengartikan kata tersebut suatu jenis makanan sayuran,5) physical distractions, hambatan ini disebabkan oleh gangguan lingkungan fisik terhadap proses berlangsungnya komunikasi. Contohnya : suara riuh orang-orang atau kebisingan, suara hujan atau petir, dan cahaya yang kurang jelas, 6)poor choice of communication channels, Adalah gangguan yang disebabkan pada media yang 
dipergunakan dalam melancarkan komunikasi. Contoh dalam kehidupan sehari-hari misalnya sambungan telepon yang terputus-putus, suara radio yang hilang dan muncul, gambar yang kabur pada pesawat televisi, huruf ketikan yang buram pada surat sehingga informasi tidak dapat ditangkap dan dimengerti dengan jelas, 7) no feed back,hambatan tersebut adalah seorang sender mengirimkan pesan kepada receiver tetapi tidak adanya respon dan tanggapan dari receiver maka yang terjadi adalah komunikasi satu arah yang sia-sia. Seperti contoh : Seorang manajer menerangkan suatu gagasan yang ditujukan kepada para karyawan, dalam penerapan gagasan tersebut para karyawan tidak memberikan tanggapan atau respon dengan kata lain tidak peduli dengan gagasan seorang manajeran radan pengembangan hipotesis

\section{METODE}

Metode yang akan dilakukan dalam kegiatan ini adalah melalui beberapa tahap: (1) Tatap Muka, yakni pengabdian langsung datang ke lokasi pengabdian untuk memperolah data. Hal ini kami lakukan pada saat menjelang maupun saat kegiatan berlangsung. Observasi berguna untuk mengetahui kondisi anak-anak di SMA Future gate dan Insan Mulia dan menentukan materi Komunikasi. Observasi sangat penting untuk mewujudkan kesuksesan kegiatan pengabdian masyarakat itu sendiri; (2) Demonstrasi, yaitu : tim pengabdi mengajarkan aplikasi promosi di media sosial kepada siswasiswi SMA Future gate dan Insan Mulia . Pengajaran akan dilakukan 4 tatap muka agar siswa-siswi SMA Future gate dan Insan Mulia .

Peserta kegiatan pengabdian masyarakat pada siswa SMA Future gate dan Insan Mulia

Pembimbing dalam kegiatan ini adalah dosen yang berada dalam program studi teknik Informasi dan mampu pada bidangnya, berikut tabel 3.2 mengenai pembimbing kegiatan.

Tabel 3.2. Daftar pembimbing pelaksana kegiatan:

\begin{tabular}{llll}
\hline No. & Kegiatan & Tutor & \\
\hline 1. & Proposal dan & Sepniyanti & \\
& Sosialisasi & & \\
2. & Materi & Mahasiswa & \\
3. & Pelaksanaan & Sepniyanti dan guru \\
& Demonstrasi & sekolah \\
4. & Evaluasi dan & Mahasiswa/Sepniyanti \\
& Laporan & \\
\hline
\end{tabular}

Pelaksanaan kegiatan ini dilakukan dalam tiga tahap, yaitu : tahap persiapan, pelaksanaan, dan evaluasi. Tahap pertama adalah tahap persiapan. Pada tahap ini, tim melakukan survei pendahuluan dan wawancara awal terhadap guru serta beberapa siswa -siswi, untuk mengetahui target kegiatan, kondisi siswa - siswi yang akan diberikan perlakuan dan menyusun rancangan kegiatan yang akan dilakukan. Tahap persiapan selanjutnya, team menyiapkan bahan - bahan yang akan dijadikan pembelajaran sebagai materi pengabdiaan masyarakat ini.

Tahap ke dua yaitu : tahap pelaksanaan. Kegiatan penyuluhan ini dilakukan team dengan memberikan informasi kepada siswa - siswi mengenai penyampaian metode picture dalam menulis paragraf narasi dan penyajian materi yang menarik serta menyenangkan.Tahap pelaksanaan dibagi 3 sesi, yaitu

\section{HASIL DAN PEMBAHASAN}

Pada pelaksanaan pembinaan siswa, tim melakukan pra kegiatan,dengan berkoordinasi dengan sekolah. Pihak sekolah memberikan beberapa data,tentang siswa yang memerlukan bimbingan konseling dan memberikan komunikasi efektif agar mereka dapat optimal dalam pembelajaran. Sekolah Menengah Atas Future gate dan SMK Insan Mulia merupakan sekolah yang menekankan kemandirian dan muatan materi sekolah bernafaskan islam. Siswa pria ada yang tinggal di asrama. Dengan kegiatan yang padat, membuat tim abdimas, menyesuaikan jadwal dengan kegiatan sekolah,mulai dari ujian nasional,ekstrakurikuler dan rapat guru dan orang tua murid tentang perpisahah sekolah .Para siswa mendapat informasi tntang kegiatan abdimas dari guru wali kelas dan kepala sekolah. Sebagian ada bertanya tentang permasalahan elajar di rumah. .Pertemuan awal, tim abdimas memperkenalkan diri dan memberi informasi tentang pentingnya komunikasi yang efektif dalam proses pembelajaran serta Bimbingan Konseling Klinis. Dari pemasalahan yang ada,tim menemukan 70\% masalah,merupakan masalah belajar dirumah, sedangkan sisanya masalah keluarga dan masalah yang berkaitan dengan masalah ekonomi keluarga. 


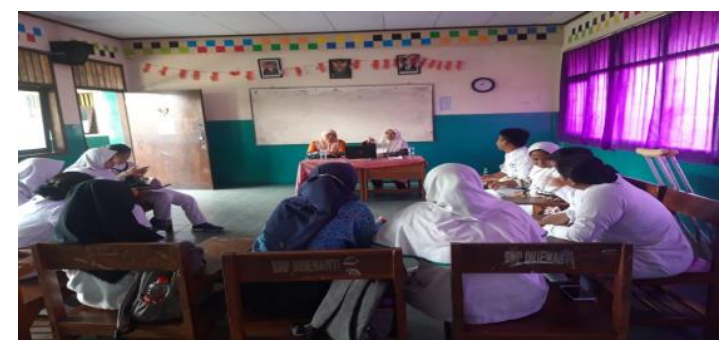

Pada gambar diatas nampak penyuluhan sedang berlangsung. Secara umum dapat dirangkum beberapa masalah BK dan solusi bebeapa siswa di SMK Insan Mulia:

Gambar. 1. Penjelasan Komunikasi Efektif kelas

Tabel 1. Temuan dan saran solusi yang dapat diterapkan

\begin{tabular}{|c|c|c|c|}
\hline No & $\begin{array}{l}\text { Nama } \\
\text { Siswa }\end{array}$ & Permasalahan & Saran Solusi \\
\hline 1 & MK & $\begin{array}{llll}\text { Jarak } & \text { kesekolah } & 5 & \text { KM,sering } \\
\text { telambat sekolah } & & \end{array}$ & $\begin{array}{l}\text { Guru BK memberikan nasehat dan } \\
\text { memanggil kedua orangtua }\end{array}$ \\
\hline 2 & MNB & $\begin{array}{l}\text { Hasil belajar menurun drastis ,sejak } \\
\text { ditinggal alm.bapak }\end{array}$ & Dibentuk kelompok belajar \\
\hline 3 & KLJ & $\begin{array}{l}\text { Sering tidur dikelas, hasil belajar } \\
\text { rendah }\end{array}$ & $\begin{array}{l}\text { Tidur awal dan memberikan jadwal belajar } \\
\text { yang ketatdiawasi keduaorangtua }\end{array}$ \\
\hline 4 & MKL & Sering gaduh dikelas & Diberikan pendekatan ,himbauan \\
\hline 5 & HJN & Bolos sekolah & $\begin{array}{l}\text { Dipanggil orang tua dan memberikan solusi } \\
\text {,dengan ikut partiipasi orangtua untuk } \\
\text { mengawasi. }\end{array}$ \\
\hline 6 & JKL & Bertengkar di sekolah & Dipanggil kedua orang tua \\
\hline 7 & GH & $\begin{array}{l}\text { Mengejek teman dan bertengkar } \\
\text { fisik }\end{array}$ & $\begin{array}{l}\text { Diberikan perlakuan ,baik nasehat dan } \\
\text { hukuman mendidik }\end{array}$ \\
\hline
\end{tabular}

Pada gambar 1 diatas siswa-siswi latihan mengutarakan pendapat dan kendala belajar . Siswa nampak antusias dalam mengikuti sesi motivasi belajar. Siswa dapat mengutarakan pendapat masing masing kepada teman,guru dan siswa kelas lain.

Pada bimbingan konseling ,guru bimbingan konseling memberikan pertanyaan ,kepada para siswa dengan cara bertanya langsung .siswa dapat mengutaran masalahmasalah belajar yang dihadapinya,baik dirumah maupun dikelas. Berikut rangkuman beberapa siswa yang menghadapi kendala pembelajaran, yang di bimbing oleh guru bimbingan Konseling. Di SMK FG:

Tabel. 2. Tabel Masalah dan Penerapan Solusi

\begin{tabular}{llll}
\hline No & Siswa & Permasalahan & Solusi dan saran \\
\hline 1 & BD & "siswa sering mengantuk didalam kelas \\
& pada jam belajar" & $\begin{array}{l}\text { Guru memberikan jadwal } \\
\text { nonton TV dan orang tua } \\
\text { melakukan pendekatan } \\
\text { komunikasi pada siswa }\end{array}$ \\
& & "Didalam kelas sering membawa HP & $\begin{array}{l}\text { Guru BK memanggil } \\
\text { orang tua untuk } \\
\text { berdiskusi bersama } \\
\text { dan telat masuk sekolah" }\end{array}$ \\
& CLS & & mencari solusi terbaik \\
\hline
\end{tabular}




\begin{tabular}{|c|c|c|c|}
\hline 3 & $\mathrm{AG}$ & $\begin{array}{l}\text { "Nilai rata rata pelajaran ujian } \\
\text { nasional dibawah } 40 "\end{array}$ & $\begin{array}{l}\text { Guru wali } \\
\text { murid,memberikan } \\
\text { pelajaran tambahan dan } \\
\text { motivasi }\end{array}$ \\
\hline 4 & DSW & $\begin{array}{l}\text { "Tidak mau mengerjakan tugas } \\
\text { pelajaran" }\end{array}$ & $\begin{array}{l}\text { 'Guru dan orang } \\
\text { tua,bersama-sama } \\
\text { memberikan dorongan } \\
\text { motivasi dan bimingan } \\
\text { belajar. }\end{array}$ \\
\hline 5 & UYH & $\begin{array}{l}\text { Sering telat masuk sekolah/pelajaran } \\
\text { awal }\end{array}$ & $\begin{array}{l}\text { Diberikan motivasi } \\
\text { kedisiplinan seta } \\
\text { bimbingan konseling }\end{array}$ \\
\hline 6 & HS & $\begin{array}{l}\text { Sering mengganggu teman di dalam } \\
\text { kelas }\end{array}$ & $\begin{array}{l}\text { Guru Bimbingan } \\
\text { konseling, memberikan } \\
\text { bimbingan dan tugas } \\
\text { tambahan.(hukuman) }\end{array}$ \\
\hline
\end{tabular}

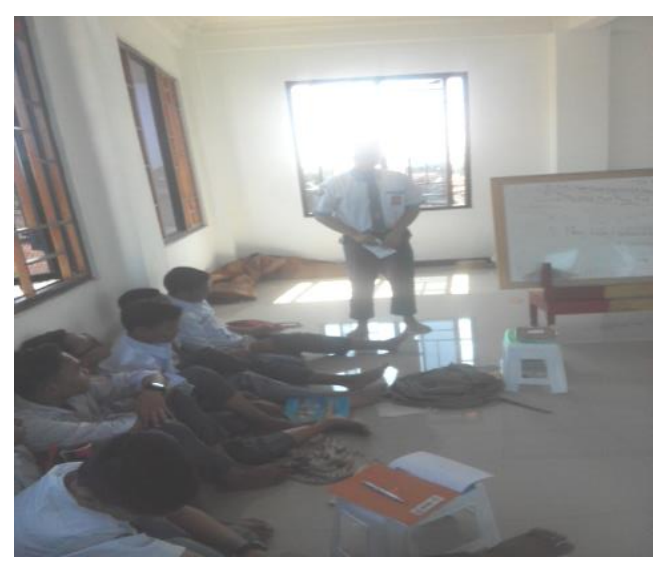

Gambar.2 Dokumentasi Latihan Komunikasi

Siswa memberikan ide dan cara dalam rangka memotivasi siswa lain,agar dapar berinteraksi dengan baik dikelas. Secara umum siswa mengisi angket setelah tim melakukan pedampingan dan mendapatkan gambaran ,seberapa manfaat kegiatan pengabdian masyarakat yang dilakukan oleh tim.

Adapun hasil angket yang diisi oleh 11 guru di sekolah hasilnya sebagai berikut :

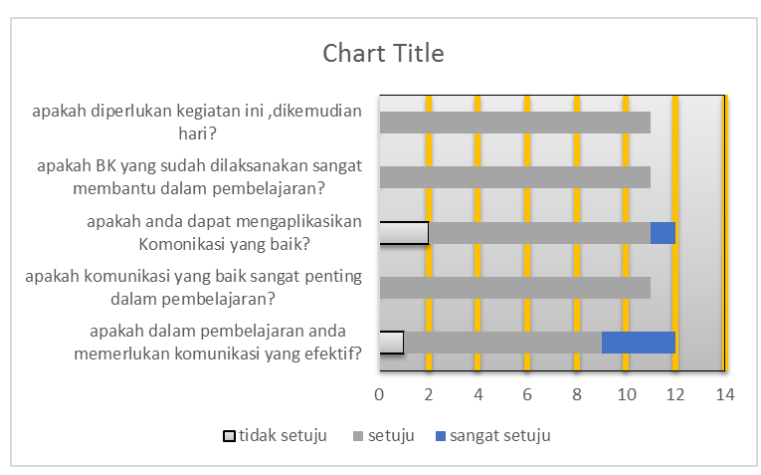

Pada grafik diatas sebagian besar guru menjawab penting . Komunikasi dan BK sangat membantu dalam pembelajaran.

\section{SIMPULAN DAN SARAN}

Beberapa hal yang dapat disimpulkan pada kegiatan pengabdian kepda masyarakat adalah,1) komunikasi merupakan unsur yang penting dalam pembelajaran dikelas,2) siswa yang mempunyai kendala dalam belajar, sebagian besar ,ditimbulkan kurangnya komunikasi dirumah dan sekolah,3) para guru diharapkan dapat menerapkan metode cooperative learning,agar dapat melatih 
komunikasi antas siswa dan dengan guru di sekolah.

Dari simpulan di atas, kami mengajukan saran dan rekomendasi sebagai berikut: (1) Guru harus meningkatkan profesionalisme, dengan memberikan pembelajarn yang kekinian dalam hal berkomunikasi; (2) Guru hendaknya memberikan pembelajaran kepada siswa -siswi, tanpa membeda - bedakan, yang berprestasi lebih ditingkatkan dan bagi siswa - siswi yang kurang agar lebih dibimbing untuk lebih maju; (3) Perkembangan zaman ,harusnya diikuti dengan pola didik yang lebih baik; (4) Kerjasama yang baik dan berkesinambungan perlu dilakukan antar lembaga sekolah, baik kepala sekolah, guru, pengawas, orang tua dan siswa - siswi dalam meningkatkan pembelajaran yang baik, efektif dalam menghasilkan pembelajaran yang bermanfaat.

\section{DAFTAR RUJUKAN}

Analisis Data Kualitatif (Buku. Sumber Tentang

Metode-metode Baru). Jakarta: UIP.

Analisis Data Kualitatif (Buku Sumber Tentang

Noornia. 1997. Penerapan belajar.

Hamonangan, R. H., \& Widiyarto, S. (2019).

Pengaruh Self Regulated Learning dan Self Control terhadap hasil belajar Bahasa Indonesia. Jurnal Dimensi Pendidikan dan Pembelajaran, 7(1), 5-10.

Juita, H. R., \& Widiyarto, S. (2019, March). The

Effectiveness of Cooperative Learning Methods: A case study of writing learning at Junior High School. In Second Conference on Language, Literature, Education, and Culture (ICOLLITE 2018). Atlantis Press

Ron Ludlow, Fergus Panton ,1992,The

Essence of Effective Communication. Prentice Hall : 1992

Suranto . 2011. Komunikasi dalam pembelajaran. Pustaka Media : Yogya

Setyowati, Y,(2005) Pola Komunikasi Keluarga

Dan Perkembangan Emosi Anak, VOLUME 2, NOMOR 1,JUNI 2005: 67-78

Widiyarto, S., \& Ati, A. P. (2018).

PENERAPANENGLISH COMMUNICATION
SKILL PADA SISWA SMP. ABDIMAS SILIWANGI, 1(2), 75-80.

Yanti, S. (2019). Peran Komunikasi Efektif

$\begin{array}{lr}\text { dan Efesien dalam } & \text { Pembelajaran. } \\ \text { JURNAL ILMIAH } & \text { WAHANA } \\ \text { PENDIDIKAN, 5(1), 51-59. }\end{array}$

